\title{
The thrifty 'catch-up fat' phenotype: its impact on insulin sensitivity during growth trajectories to obesity and metabolic syndrome
}

\author{
AG Dulloo $^{1}$, J Jacquet ${ }^{2}$, J Seydoux ${ }^{2}$ and J-P Montani ${ }^{1}$ \\ ${ }^{1}$ Division of Physiology, Department of Medicine, University of Fribourg, Switzerland and ${ }^{2}$ Faculty of Medicine, University of \\ Geneva, Switzerland
}

\begin{abstract}
The analyses of large epidemiological databases have suggested that infants and children who show catch-up growth, or adiposity rebound at a younger age, are predisposed to the development of obesity, type 2 diabetes and cardiovascular diseases later in life. The pathophysiological mechanisms by which these growth trajectories confer increased risks for these diseases are obscure, but there is compelling evidence that the dynamic process of catch-up growth per se, which often overlaps with adiposity rebound at a younger age, is characterized by hyperinsulinemia and by a disproportionately higher rate in the recovery of body fat than lean tissue (i.e. preferential 'catch-up fat'). This paper first focuses upon the almost ubiquitous nature of this preferential 'catch-up fat' phenotype across the life cycle as a risk factor for obesity and insulin-related complications - not only in infants and children who experienced catch-up growth after earlier fetal or neonatal growth retardation, or after preterm birth, but also in adults who show weight recovery after substantial weight loss owing to famine, disease-cachexia or periodic dieting. It subsequently reviews the evidence indicating that such preferential catch-up fat is primarily driven by energy conservation (thrifty) mechanisms operating via suppressed thermogenesis, with glucose thus spared from oxidation in skeletal muscle being directed towards de novo lipogenesis and storage in white adipose tissue. A molecular-physiological framework is presented which integrates emerging insights into the mechanisms by which this thrifty 'catch-up fat' phenotype crosslinks with early development of insulin and leptin resistance. In the complex interactions between genetic constitution of the individual, programming earlier in life, and a subsequent lifestyle of energy dense foods and low physical activity, this thrifty 'catch-up fat' phenotype - which probably evolved to increase survival capacity in a hunter-gatherer lifestyle of periodic food shortages - is a central event in growth trajectories to obesity and to diseases that cluster into the insulin resistance (metabolic) syndrome.
\end{abstract}

Keywords: thermogenesis; catch-up growth; adiposity rebound; weight fluctuation; weight cycling; early programming

\section{Weight dynamics and risks for diseases}

Dynamic changes in body weight have long been recognized to be important indicators of risks for later debilitating diseases. Whereas severe weight loss or impaired growth can lead to muscle wastage and to increased susceptibility to infections and organ dysfunctions, the development of obesity predisposes to type 2 diabetes and cardiovascular diseases, with insulin resistance as a relatively early development in the pathogenesis of these chronic diseases. In more recent decades, an increasing body of evidence has also

Correspondence: Dr AG Dulloo, Division of Physiology, Department of Medicine, University of Fribourg, Rue du Musée 5, CH-1700 Fribourg, Switzerland.

E-mail: abdul.dulloo@unifr.ch implicated the dynamic process of recovering body weight whether after weight loss or after growth retardation - in the pathogenesis of these chronic diseases (Figure 1).

Weight recovery after weight loss in adults

High cardiovascular morbidity and mortality have often been reported in men and women who in young adulthood experienced marked fluctuations in body weight. ${ }^{1-5}$ In the most recently published large population-based study ${ }^{6}$ in the US (National Health and Nutrition Examination Survey I, $n=8479)$ that included multiple weight measurements between 1971 and 1992, weight fluctuation was also associated with a higher risk of all-cause and cardiovascular mortality, even after adjustment for pre-existing disease, initial body mass index (BMI) and the exclusion of those in 


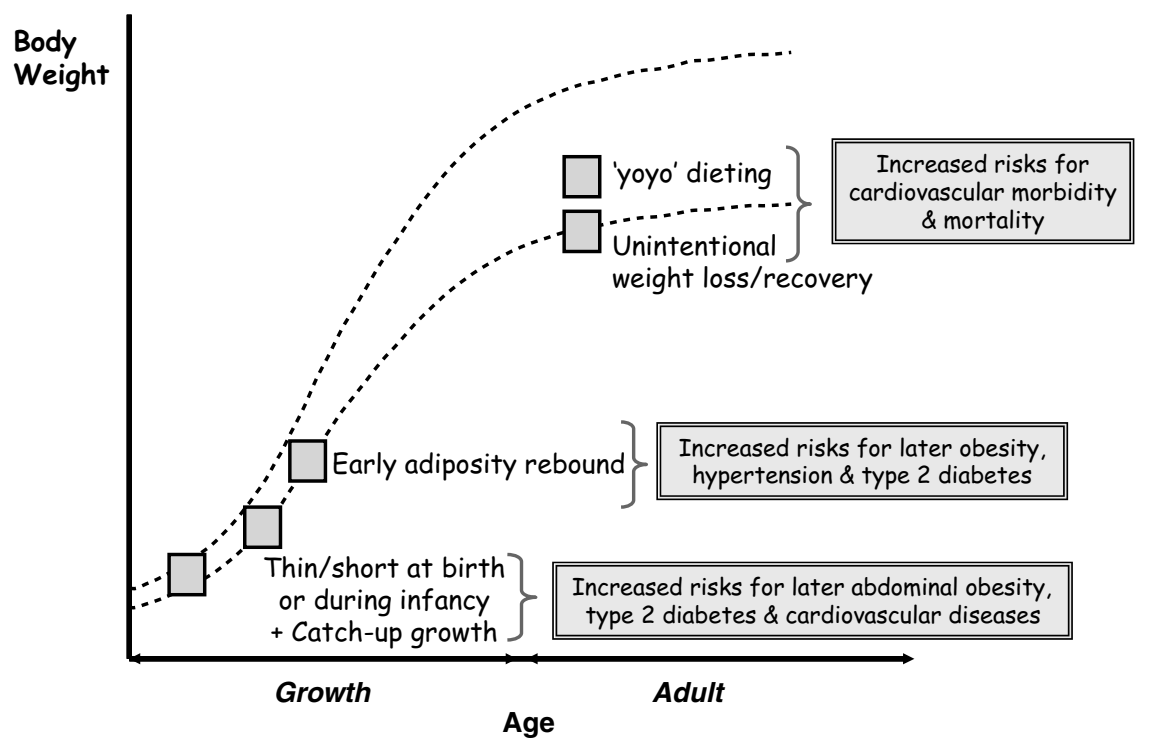

Figure 1 Schematic representation of risks for chronic diseases resulting from large fluctuations in body weight earlier in life during the growth period (fetal, neonatal, infancy and childhood) or in young adulthood.

poor health and the incapacitated. ${ }^{6}$ As these associations were found to be independent of excess weight and trend of body weight over time, they are hence of clinical relevance not only for the obese 'yoyo' dieters who fail to maintain their lost weight, but also for non-obese population groups whose weight fluctuates for a variety of reasons, namely (i) because of recurring chronic diseases with episodic remissions, such as those suffering from chronic alcoholism and gastrointestinal diseases, and (ii) because of 'weight cycling' behaviors resulting from periodic dieting such as in athletes engaged in 'power' sports with weight categories (wrestlers, boxers and weightlifters), or in people with perceived, rather than real, excess weight in the relentless pursuit for thinness (Ref. Montani et al., ${ }^{7}$ for review). In fact, the evidence for higher cardiovascular risks owing to large swings in body weight is more compelling in cohorts from the general population than from obese populations per se. In some of these former cohorts, even a single cycle of substantial weight loss and weight recovery in young adulthood was found to be a risk factor for subsequent coronary heart diseases and mortality. ${ }^{1,2}$ These conclusions, which were derived from retrospective studies in Europe and North America have recently been strengthened by several long-term studies in Japan which show increased risk for various components of the metabolic syndrome (hyperinsulinemia, hypertriglyceridemia, high low-density lipoprotein cholesterol, high fasting glucose and abdominal obesity) both in overweight and in normal-weight persons with large weight fluctuations. ${ }^{8-10}$

\section{Catch-up growth after poor fetal or neonatal growth}

By far the most compelling evidence linking large fluctuations in body weight as a risk factor for later diseases derive from longitudinal studies extending throughout an entire generation in many parts of the world. These epidemiological studies have suggested that people who had low birth weight or whose growth faltered during infancy and childhood, but who subsequently showed catch-up growth have higher susceptibility for the development of obesity, type 2 diabetes and cardiovascular diseases later in life. ${ }^{11-16}$ For example, the analysis of data from Finland indicates that men who were small at birth and thin during infancy but subsequently showed catch-up growth and became overweight in childhood were found to have a fivefold increase in mortality compared with men with a high BMI at birth and lean in childhood. ${ }^{11}$ Further evidence that catch-up growth, though beneficial in the short term, might be detrimental in the long term can be derived from studies conducted in countries undergoing nutrition transition. Studies from South Africa, Brazil, Russia, China and India suggest that stunted children have a 2-8 times greater risk of becoming overweight ${ }^{17}$ and/or have increased risks for cardiovascular and metabolic disorders. ${ }^{18-21}$ Finally in a detailed retrospective longitudinal study of 8760 men and women born in Helsinki with records of their monthly changes in body size from birth to 2 years of age, as well as annual changes through 11 years of age, it was shown that men and women who were small at birth and thin during infancy and subsequently showed catch-up growth had higher risks of coronary events. ${ }^{16}$ These higher risks were also associated with insulin resistance, and were more strongly related to the tempo of childhood gain in BMI than to the BMI attained at any particular age, thereby underscoring the fundamental importance of the dynamic aspects of catch-up growth per se on later insulin resistance and cardiovascular risks. 
Catch-up growth after preterm birth

Catch-up growth in those born preterm has also been linked to insulin resistance later in life. Although the incidence of obesity, type 2 diabetes or cardiovascular diseases among people who were born prematurely is unknown (as the first generation of very premature infants is only now surviving in substantial numbers), children and adolescents who showed neonatal catch-up growth after being born prematurely, irrespective of whether they were appropriate for gestational age (AGA) or small for gestational age (SGA), have reduced insulin sensitivity and increased circulating insulin levels ${ }^{22,23}$ Furthermore, in a prospective long-term follow-up into young adulthood of men and women born very preterm, catch-up growth during early infancy was a predictor of adult fat accumulation ${ }^{24}$ as well as central fat distribution and higher insulin levels at 19 years of age. ${ }^{25}$

\section{Catch-up growth after premature adiposity rebound}

These long-term health hazards of catch-up growth also seem to overlap with another major childhood predictor of later obesity, that is, an early (younger) age for adiposity rebound - a term first coined by Rolland-Cachera et al. ${ }^{26}$ to refer to the age that corresponds to the second rise in the BMI curve, and which normally occurs between 5 and 7 years in the Western world. Investigations in many countries have confirmed this association between an earlier age for adiposity rebound (often $<3$ year) with increased risk for adult obesity and hypertension. ${ }^{26,27}$ Furthermore, it has been shown that, independently of birth weight, a pattern of poor weight gain before an early adiposity rebound, followed by increased BMI after the rebound (i.e. catch-up growth after onset of early adiposity rebound) seems to confer increased risk for impaired glucose tolerance and type 2 diabetes in adulthood. $^{28-30}$ Whether children who have an early adiposity rebound had a low-weight gain during infancy because of exposure to a weaning or post-weaning infant diet that is low in fat but high in protein, ${ }^{31}$ followed by a childhood diet that is high in fat, is currently controversial. ${ }^{27}$ However, as reviewed by Taylor et al., ${ }^{27}$ an early age for adiposity rebound has also been recorded in a number of pediatric conditions characterized by high subsequent obesity, including children treated for adrenal 21-hydroxylase deficiency, hypothyroidism, hyperphenylalaninemia and acute lymphoblastic leukemia - all conditions that are generally associated with perturbed growth before the premature adiposity rebound that overlaps with catch-up growth.

Catch-up growth: a state of insulin resistance

The mechanisms by which catch-up growth could lead to (or precipitate towards) such chronic metabolic diseases remain obscure, amid theories of early (fetal or neonatal) programming which postulate that food deprivation, malnutrition or other insults, particularly when they occur during critical periods of growth and development, can lead to lasting alterations in structures and functions of tissues (namely in pancreatic $\beta$ cells, muscle, adipocytes, kidney and liver), and in the resetting of major neuroendocrine systems. ${ }^{32,33}$ Such 'programming' or 'imprinting', although adaptive during the period of limited supply of nutrients, is thought to contribute to the increased risks for diseases during improved nutrition and catch-up growth later in life. Whatever the mechanisms by which such programming may predispose to chronic metabolic diseases, however, several lines of evidence point to the dynamic phase of catch-up growth per se as a state of insulin resistance. A higher plasma insulin response to a glucose load has long been demonstrated during catch-up growth in infants and children who were born SGA, ${ }^{34}$ and more recently, strong associations have been described in many countries between thinness during early infancy and an elevated plasma insulin during catch-up growth later in childhood. ${ }^{35,36}$ These findings, together with recent prospective studies from Chile $^{37}$ indicating that reduced insulin sensitivity could be related to catch-up growth in SGA infants as early as at 1 year of age, underscore the development of insulin resistance as an early feature of the mechanisms by which catch-up growth might confer increased risk for later diseases. Whether this early state of insulin resistance precedes or is preceded by excess adiposity or preferential abdominal fat deposition is at present unknown. There is however converging evidence which suggests that the insulin-resistant state of catch-up growth is intimately linked with a disproportionately faster rate to gain body fat rather than lean tissue, ${ }^{38}$ that is, to a preferential acceleration of fat recovery or 'catch-up fat'

\section{The ubiquitous 'catch-up fat' phenotype}

From a historical perspective, early realization of excessive fat deposition during catch-up growth in humans can be traced to the commentary of Widdowson and Shaw ${ }^{39}$ on studies conducted in the 1960's on malnourished children in Jamaica. They pointed out that when children recovering from marasmus or marasmic-kwashiorkor in the study of Ashworth $^{40}$ had reached their expected weight-for-height, their bodies contained $25-37 \%$ of fat, with a mean value of $30 \%$, which is more than that found by Garrow et al. ${ }^{41}$ for clinically well-nourished children in the same age range. There have been many more reports from nutritional rehabilitation studies conducted in developing countries that gains in body weight, even during apparently successful catch-up growth in infants and children, are largely fat, with the reconstitution of lean body mass lagging behind. ${ }^{42-47}$

\section{Catch-up fat in infants/children born SGA}

This catch-up fat phenotype, and its association with hyperinsulinemia and impaired glucose homeostasis, has more recently been documented in children born SGA in 
developed countries. In a study conducted in Switzerland, prepubertal children born SGA were found to have more body fat and less lean tissue, as well as lower glucose oxidation rates, than weight-matched controls, ${ }^{48}$ and a recent longitudinal study in Spain $^{49}$ has revealed that already between ages of 2 and 4.5 years, children born SGA gained more abdominal fat and total body fat (assessed by dual energy X-ray absorptiometry (DEXA) scan) and less lean tissue than children born AGA despite similar gains in weight and BMI (Figure 2a). By about 4 years of age, these children born SGA had greater adiposity and showed lower insulin sensitivity than children born AGA. ${ }^{49}$ Another recent longitudinal study, using magnetic resonance imaging to assess adipose tissue volume, indicated that infants born SGA and showing complete catch-up in relation to head growth and adiposity by 6 week after birth, still showed incomplete catch-up in length and weight. ${ }^{50}$ These differences in body composition, associated with impaired glucose metabolism, may persist into adulthood as suggested by studies from Finland, ${ }^{51}$ and from England using DEXA scan, ${ }^{52}$ indicating that for the same BMI as age-matched controls, healthy elderly individuals born SGA have $3-5 \mathrm{~kg}$ less lean tissue mass, more fat mass, and a more central fat distribution. Similarly, studies from Denmark in cohorts of healthy young men born SGA indicate that they have slightly less lean tissue mass and slightly more body fat, but clearly higher abdominal fat mass ${ }^{53}$ than age-matched controls of similar
BMI, or that they showed reduced forearm glucose uptake ${ }^{54}$ and reduced muscle expression of key proteins involved in insulin signaling and glucose transport. ${ }^{55}$ It is presently unknown whether these insulin-related impairments in adults born SGA precede or are preceded by preferential abdominal fat deposition, excess circulating lipids or ectopic fat storage, all of which have been implicated in the development of insulin resistance. However, these studies in infants, children and adults born SGA point to an early but long-lasting impairment in glucose homeostasis and body composition that can be related to preferential catchup fat during catch-up growth.

\section{Catch-up fat in infants born preterm}

There is also evidence that the phenomenon of preferential catch-up fat also occurs during catch-up growth in infants born preterm - a population group that has been reported to show reduced insulin sensitivity and compensatory hyperinsulinemia in childhood, adolescence and early adulthood. $^{22-25}$ Indeed, the application of whole-body magnetic resonance - that allows adipose tissue imaging and its quantification - has indicated that in infants born extremely preterm ( $<32$ week gestational age) and profoundly deficient in adipose tissue, the subsequent accelerated post-natal growth was accompanied by accelerated fat gain such that, at their expected time of delivery several weeks later, these
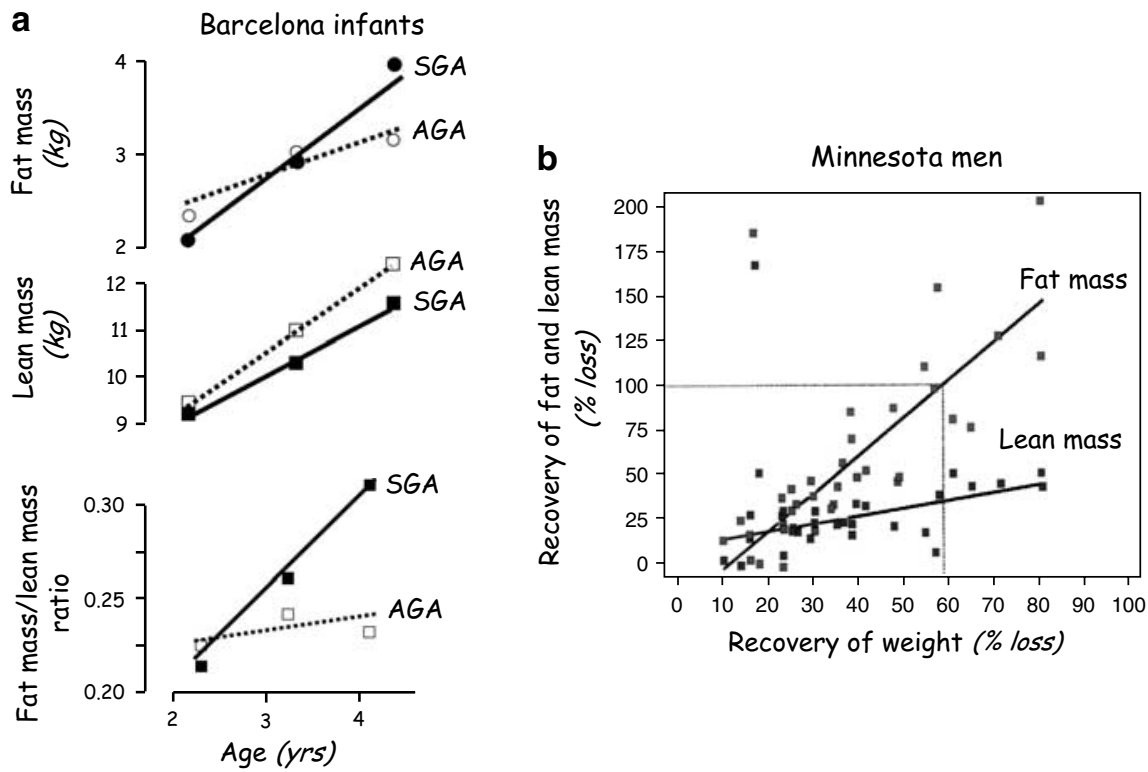

Figure 2 Longitudinal studies of human body composition demonstrating preferential catch-up fat in infants born SGA ( $n=29$ ) compared to controls born AGA $(n=22)(a)$, and in adults recovering weight after semistarvation in the Minnesota Experiment (b). The figures in panel (a) (Barcelona infants) are derived from data on body weight and body composition (lean body mass and \%fat) assessed by DEXA scan in the study of Ibanez et al. ${ }^{49}$ Note that (i) the velocity of fat gain (slope of fat mass vs age) is about twofold greater in the infants born SGA than in controls born AGA, and that (ii) the relatively constant ratio of fat mass to lean tissue mass in infants born AGA contrasts sharply with the marked quasilinear increase in this ratio in infant born SGA over the 2-year period of body composition study. The figure in (b) (Minnesota men) is derived from a reanalysis of body composition data (assessed by underwater weighing) after 12 weeks of restricted refeeding on a low-fat diet in the 32 men participating in the Minnesota study of experimental semistarvation of Keys et al. ${ }^{62}$; by the time the recovery of fat mass is $100 \%$, the recovery of lean body mass is still below $50 \% .^{74}$ 
preterm infants reached the same total adiposity as termborn infants despite the fact that they were lighter and shorter. ${ }^{56}$ Taken together, these studies further underscore the occurrence of preferential catch-up fat with lean tissue lagging behind in preterm infants showing post-natal catchup growth, and their predisposition to insulin resistance later in life.

\section{Catch-up fat in children showing early adiposity rebound}

As emphasized above, an early age for childhood adiposity rebound, which is also a risk factor for later obesity, diabetes and hypertension, is often reported to be preceded by lowweight gain during infancy. However, because childhood adiposity rebound is determined using serial measurements of BMI, it has been questioned as to whether early rebound reflects greater relative weight gain or reduced height velocity, and whether the actual change in body composition occurring during this time is a reflection of increased body fat or increased lean body mass. ${ }^{57}$ There is now evidence from longitudinal studies in children that differences in BMI during the period of adiposity rebound are caused specifically by alterations in weight velocity rather than in height velocity, ${ }^{58}$ and in body fat rather than in lean body mass, ${ }^{59}$ and that children undergoing early adiposity rebound gained fat at a faster rate than children who rebounded at a later age. ${ }^{59}$ It follows therefore that children showing an early age for adiposity rebound following lowweight gain also exhibit the preferential catch-up fat phenotype that is characteristic of catch-up growth.

\section{The catch-up fat phenotype in adults}

The phenomenon of preferential catch-up fat - that is, disproportionate rate in recovering fat mass relative to lean tissue mass - has in fact been pointed out since the turn of the 20th century in adults recovering weight after diseases or famines. ${ }^{60-62}$ In particular, Debray et al. ${ }^{61}$ noted that the early increase in the weight of prisoners transferred from German concentration camps to a Paris hospital in a condition of severe starvation was largely owing to the accumulation of fat rather than to the rebuilding of muscles. Keys et $a .^{62}$ in their study on long-term experimental semistarvation and refeeding in conscientious objectors of war found that when body fat was $100 \%$ recovered, the recovery of muscle mass or fat-free mass (FFM) was less than $40 \%$ of prestarvation values (Figure 2 , panel b). By the time that FFM had been fully recovered, body fat had exceeded the prestarvation values by more than $75 \% .{ }^{62,63}$ These findings led Keys et al. ${ }^{62}$ to describe such preferential fat accumulation and fat overshooting as 'post-starvation obesity'. Some 50 years later, a similar conclusion was reached by Weyer et al. ${ }^{64}$ in their follow-up study of men and women who lost about $15 \%$ of their body weight during exposure to modest energy restriction sustained over 2 years during confinement in Biosphere 2, a self-contained ecological 'miniworld' and prototype planetary habitat built in Arizona. Although their body weight returned to pre-entry values 6 months after exit, the weight regained was found to be almost exclusively accounted for by an increase in body fat. Over the past few decades, this phenomenon of fat recovery predominating over muscle reconstitution has also been reported in hospitalized adult patients recovering from severe weight losses owing to poverty-related undernutrition, ${ }^{65}$ anorexia nervosa ${ }^{66}$ and various pathophysiological 'hypermetabolic' conditions including cancer, ${ }^{67}$ septic shock $^{68}$ acquired immunodeficiency syndrome ${ }^{69}$ and Parkinson's disease in the elderly. ${ }^{70}$ Specifically in the case of women with anorexia nervosa (illness that often begin during adolescence), normalization of body weight is often reported to be associated with a central adiposity phenotype, assessed as increased truncal fat and visceral adipose tissue. ${ }^{71}$

\section{Regulation of fat storage during catch-up fat}

Thus, the preferential catch-up fat phenotype is a common denominator in many situations of large weight fluctuations whether during catch-up growth in infants and children born preterm, AGA or SGA, or during weight recovery in young and elderly adults. A fundamental question that arises therefore is what is known about the processes that regulate the body fat stores during preferential catch-up fat, and how do these processes confer increased susceptibility to the development of insulin resistance?

\section{Control systems regulating catch-up fat}

From a standpoint of systems physiology, there are three fundamental autoregulatory control systems that could be implicated in catch-up fat:

(i) An overcompensatory hyperphagic drive, particularly during catch-up growth or weight recovery on energydense foods rich in fats and refined carbohydrates,

(ii) a shift in the control of the body's partitioning of energy from lean to fat tissue, particularly with diets that may be inadequate in specific nutrients (protein, minerals, vitamins and so on) for optimal protein synthesis, and

(iii) an increase in the efficiency of the metabolic machinery, that is, energy conservation through the suppression of thermogenesis - which is embodied in the concept of a 'thrifty metabolism'.

They may all contribute to the accelerated rate of fat recovery whether during growth or adulthood. There is indeed some evidence to suggest that post-natal catch-up growth may be driven by hyperphagia, as indicated by early feeding studies in infants, ${ }^{72}$ and that the occurrence of refeeding hyperphagia in children and adults is driven by the impetus to recover both fat mass ${ }^{63}$ and lean body mass. ${ }^{63,73}$ However, the phenomenon of preferential catch-up fat can 
be shown to occur in the absence of hyperphagia, ${ }^{38,74}$ and without a shift in energy partitioning from lean to fat tissue, ${ }^{74}$ which therefore underscore a central role for an enhanced metabolic efficiency (i.e. suppressed thermogenesis) as a fundamental physiological reaction to growth retardation or weight loss. There are therefore close associations between weight recovery/catch-up growth, a high metabolic efficiency underlying catch-up fat, and the development of obesity and/or insulin-related complications later in life. Consequently, it follows that sustained reduction in energy expenditure per se (owing to suppressed thermogenesis in certain organs/tissues) - for the purpose of enhancing the efficiency of fat recovery - is also involved in the pathogenesis of these chronic metabolic diseases.

\section{Role of 'adipose-specific' suppression of thermogenesis}

There is indeed converging evidence from experimental studies of prolonged starvation and refeeding in adult humans ${ }^{62,64,74}$ and in actively growing animals, ${ }^{75-82}$ that an elevated efficiency for catch-up fat is a phenomenon that occurs at all ages, and that it is a carryover effect of the suppression of thermogenesis (i.e. energy conservation mechanisms) that occurred in the preceding period of food deprivation. This has been referred to as adipose-specific control of thermogenesis'; $;{ }^{83}$ that is, a control system that has a slow time-constant by virtue of its response to signals arising only from the state of depletion (or delayed expansion) of the body's fat stores. In this autoregulatory feedback system, signals from the depleted adipose fat stores exert a suppressive effect on thermogenesis. Support for the existence of a control system linking depletion of fat stores and suppressed thermogenesis in humans comes from the reanalysis $^{74,84}$ of longitudinal data on changes in basal metabolic rate (BMR) and in body composition from the classic 'Minnesota Experiment' of semistarvation and refeeding. ${ }^{62}$ In this study, 32 healthy men of normal body weight were subjected to 24 weeks of semistarvation (during which they lost $\sim 25 \%$ of initial body weight), followed by 12 weeks of restricted refeeding on diets relatively low in fat $(\sim 20 \%$ fat by energy). As shown in Figure 3, there is a positive relationship between the deviation in body fat and the change in adjusted BMR, an index of altered thermogenesis calculated from the change in BMR after adjusting for losses of FFM and fat mass. In other words, the greater the degree of fat depletion during starvation, the greater the reduction in adjusted BMR and hence in the degree of suppression of thermogenesis. A similar relationship was also found after the 12-week period of restricted refeeding, that is, the lower the degree of fat repletion, the greater the extent of reduction in residual BMR and hence the greater the degree of reduction in thermogenesis. ${ }^{84}$ Taken together, the relationship between suppressed thermogenesis and fat depletion during phases of both weight loss and weight recovery indicates the operation of a control system with a negative feedback loop between thermogenesis and the state of depletion of fat stores. Although similar type of evidence linking fat depletion (or delayed expansion of the fat stores) and suppressed thermogenesis during catch-up growth in
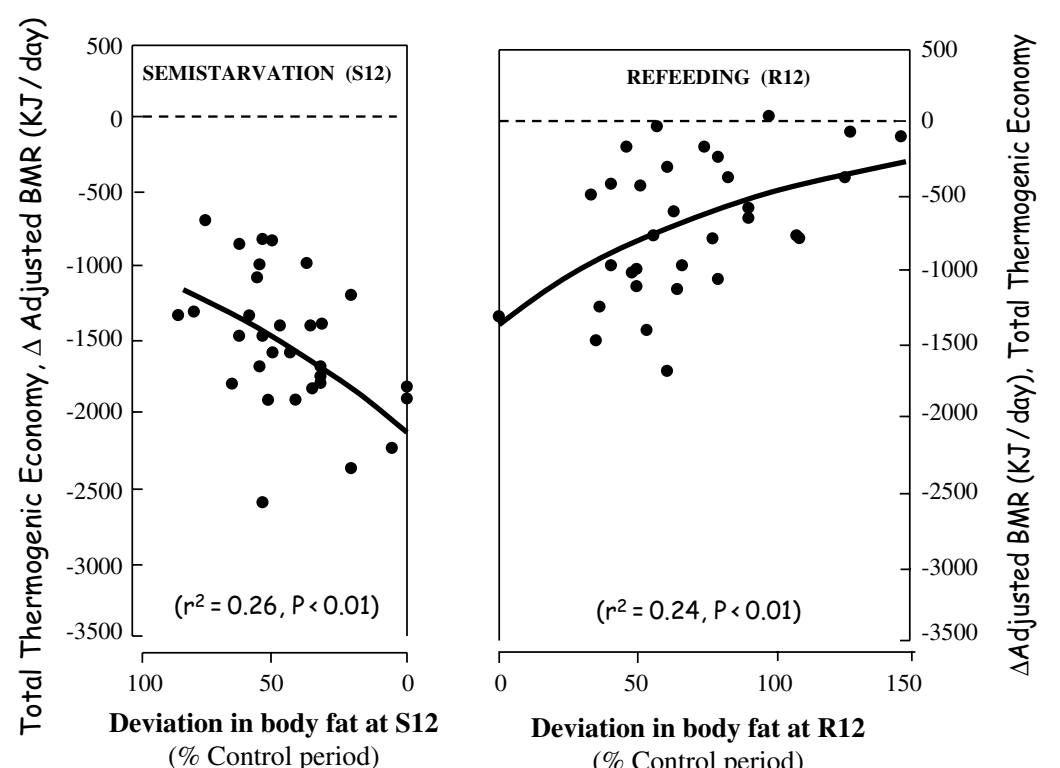

Figure 3 Minnesota Experiment of human starvation and refeeding revisited: the relationship between suppressed thermogenesis, assessed as change in BMR adjusted for changes in FFM and fat mass, and the state of depletion of body fat stores during weight loss (S12, week 12 of semistarvation) and weight recovery (R12, week 12 of restricted refeeding). The relationship between suppressed thermogenesis and fat depletion during phases of both weight loss and weight recovery suggests the operation of a control system with a negative feedback loop between thermogenesis and the state of depletion of fat stores. Adapted from Refs. Dulloo and jacquet. ${ }^{83,84}$ 
humans is not available, direct evidence for an adiposespecific suppression of thermogenesis, the role of which is to specifically accelerate body fat recovery, can be derived from studies of complete energy balance in growing rats regaining weight after semistarvation (Figure 4). Under conditions whereby the rehabilitated animals were pair-fed to weight-matched controls, the rate of protein deposition was found to be the same as in controls, but that of fat deposition was increased by more than twofold. This was shown to be the result of 10-15\% lower energy expenditure during the first 2-3 weeks of isocaloric refeeding. ${ }^{79,80,83} \mathrm{~A}$ number of factors that could theoretically contribute to this difference in energy expenditure between refed and control animals (age difference, physical activity and feeding pattern) have been evaluated and shown to have a minimal impact on the difference in energy expenditure between the two groups. Consequently, under these conditions of refeeding, the lower energy expenditure in the refed animals is essentially a result of energy being spared owing to sustained suppression of thermogenesis for the purpose of catch-up fat. Taken together, these findings in humans and in animals support the existence of an autoregulatory control system that participates in the regulation of catch-up growth by sustained suppression of thermogenesis, and suggest that the energy thus conserved is directed specifically for the recovery of fat mass rather than that of lean mass, that is, a thrifty metabolism specific for preferential catch-up fat.

\section{The thrifty metabolism that drives catch-up fat: impact on insulin sensitivity}

As skeletal muscle is an important site for energy conservation during starvation, ${ }^{62,64,85-88}$ the control system underlying this adipose-specific control of thermogenesis could operate as a feedback loop between adipose tissue triglyceride stores and skeletal muscle metabolism. As depicted in Figure 5, it could comprise a sensor(s) of the state of depletion (or delayed expansion) of the fat stores, signal(s) dictating the suppression of thermogenesis as a function of the state of depletion of the fat stores, and an effector system mediating thermogenesis in skeletal muscle. ${ }^{83}$ At present, our understanding of the components of this system is fragmentary. However, as skeletal muscle is the major site for insulin-mediated glucose disposal, a reduction in the metabolic rate of muscle would therefore result in a reduction in glucose utilization, leading to hyperinsulinemia. ${ }^{89}$ This in turn, would serve to redirect the spared glucose towards de novo lipogenesis and fat storage in adipose tissue.

\section{Muscle-adipose glucose redistribution}

Support for this 'glucose redistribution hypothesis' can be derived from studies in our animal model of catch-up fat driven solely by suppressed thermogenesis. These have indicated that refeeding on a low-fat diet resulted in a more pronounced elevation in plasma insulin after a glucose


Figure 4 Sustained reduction in energy expenditure and accelerated fat deposition (catch-up fat) in a rat model of controlled refeeding after semistarvation. Changes in body composition and in energy balance were assessed over three successive periods of 10 days in refed animals pair-fed to weight-matched (WM) controls. The lower energy expenditure during refeeding persists for 2-3 weeks, and is due almost entirely to a sustained suppression of thermogenesis that drives catch-up fat during weight recovery; ${ }^{* *} P<0.01 ;{ }^{* \star} P<0.001$ compared with WM controls. Adapted from Ref. Dulloo and Jacquet. ${ }^{83}$ 


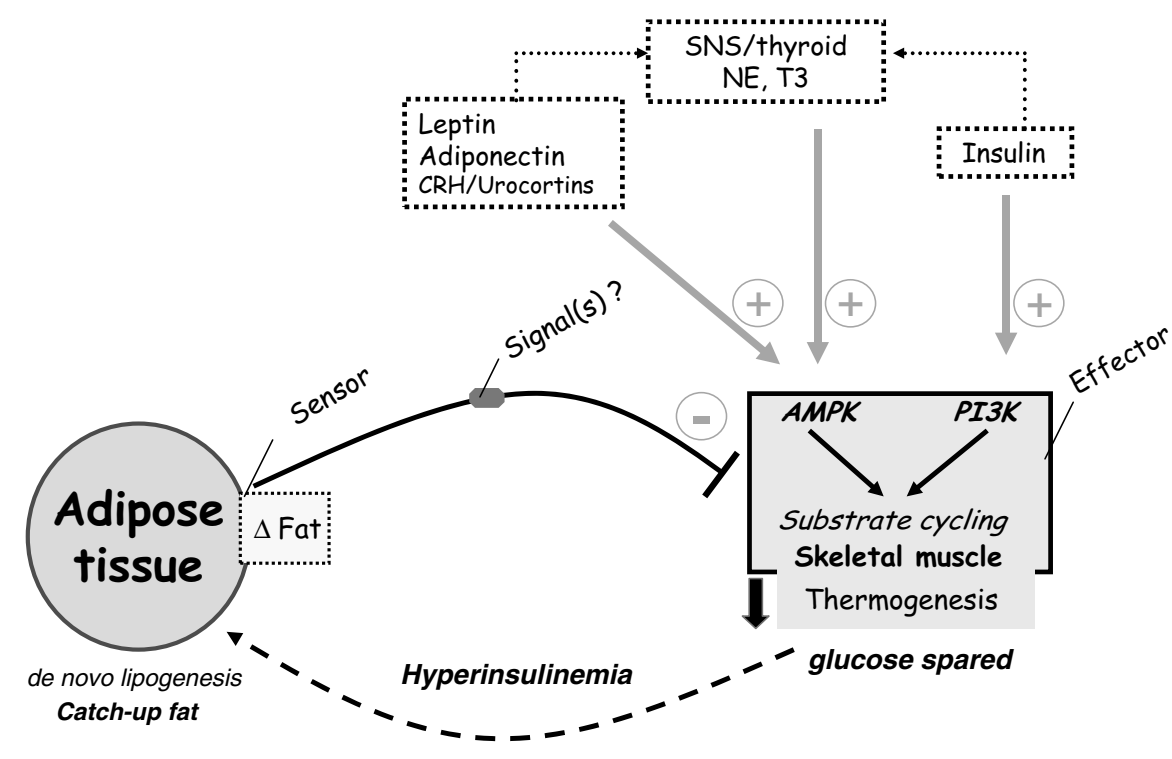

Figure 5 Schematic diagram depicting mechanisms by which the thrifty catch-up fat phenotype, driven by the adipose-specific suppression of thermogenesis, may crosslink with early development of insulin and leptin resistance. The model is built upon emerging evidence that an important thermogenic effector system in skeletal muscle is mediated by substrate cycling between de novo lipogenesis and lipid oxidation, ${ }^{93,94}$ and it is orchestrated by PI3K and AMPK under the influence of insulin, leptin, adiponectin and other hormones (e.g. urocortins). ${ }^{93,94,98}$ These hormones can interact to stimulate thermogenesis via the enhancement of AMPK and $\mathrm{PI3K}$ signaling either by acting directly on skeletal muscle, or centrally through the sympathetic-thyroid axis via norepinephrine (NE) and triiodothyronine (T3). By interfering with PI3K and/or AMPK signaling in skeletal muscle, the actions of the adipose-specific signal(s) that sense the state of depletion (or delayed expansion) of the adipose tissue fat stores will suppress skeletal muscle thermogenesis, which during refeeding will lead to concomitant insulin and leptin resistance. The resulting hyperinsulinemia serves to redirect the glucose spared from oxidation in skeletal muscle towards de novo lipogenesis and fat storage in white adipose tissue.

load, ${ }^{90}$ and that under conditions of hyperinsulinemiceuglycemic clamps in vivo, insulin-stimulated glucose utilization in refed animals is lower in skeletal muscle but higher in white adipose tissue, ${ }^{91}$ thereby suggesting a state of insulin resistance in skeletal muscle and insulin hyperresponsiveness in white adipose tissue. Furthermore, the fact that fatty acid synthase activity is higher in white adipose tissue from refed animals than from controls, suggest enhanced conversion of glucose to lipids in the adipose tissue fat stores. ${ }^{91}$ Of particular importance in these studies comparing refed and control animals is that this redistribution of glucose utilization away from skeletal muscle towards de novo lipogenesis and fat storage in adipose tissue can be demonstrated in the absence of between-group differences in energy intake, lean tissue mass, total body fat mass, regional fat distribution or in circulating free fatty acids. Similarly, the state of insulin resistance in skeletal muscle of the refed animals cannot be attributed to excess lipid storage in muscle cells, as histological staining of muscles revealed that intramyocellular lipid content in muscles from refed animals was not higher than in controls. ${ }^{91}$ Taken together, these data suggest that the muscle insulin resistance and adipose tissue insulin hyperresponsiveness in the refed animals are not related to an excess substrate (free fatty acid) supply or to increased body fat or ectopic fat storage, but can be linked to the state of suppressed thermogenesis per se. In other words, the mechanisms that lead to suppressed skeletal muscle thermogenesis (in favor of catch-up fat) are interlinked with those that lead to insulin resistance during catch-up growth. By what molecular mechanisms this suppression of thermogenesis is brought about, and how these mechanisms of suppressed thermogenesis might crosslink with early development of skeletal muscle insulin resistance are therefore fundamental issues that need to be addressed towards understanding how catch-up growth confers increased susceptibility to insulin resistance and hyperinsulinemia.

\section{Molecular crosslinks between suppressed thermogenesis and insulin resistance}

As the concentrations of key 'adiposity' hormones that might be implicated in the link between glucose metabolism and thermogenesis in skeletal muscle (namely insulin and leptin) are rapidly restored to control levels upon transition from starvation to refeeding, ${ }^{89,90}$ our current working hypothesis, therefore, is that the suppression of thermogenesis and concomitant insulin resistance in skeletal muscle are brought about through the inhibition of mechanisms by which these (and other) hormones interact to activate thermogenesis in skeletal muscle. ${ }^{89}$ Although the nature of these postulated adipose-specific signal(s) that inhibit thermogenesis in skeletal are unknown, there is emerging evidence that their inhibitory actions on muscle thermogenesis could occur through interference with the activation of phosphatidylinositol 3-kinase (PI3K) or AMPactivated protein kinase (AMPK). Indeed, ex-vivo studies of 
microcalorimetry in intact skeletal muscle have shown that PI3K and AMPK signaling - which are well known to influence insulin sensitivity in this tissue - are both required for hormonal stimulation of thermogenesis in this tissue as the direct thermogenic effects of leptin or corticotropinreleasing hormone in skeletal muscle can be inhibited by selective inhibitors of either AMPK or PI3K. ${ }^{92-94}$ On the basis of these findings, it follows that either diminished PI3K and/or AMPK signaling in skeletal muscle could constitute impairments that are common to pathways that lead to both suppressed thermogenesis and to resistance to the actions of insulin and leptin during catch-up growth (Figure 5). This notion is indeed supported by data from our laboratory ${ }^{95}$ indicating diminished basal and insulin-stimulated PI3K activity in skeletal muscle of rats showing catch-up fat driven by suppressed thermogenesis during refeeding on a low-fat diet, with additional impairments in leptin-induced activation of AMPK during isocaloric refeeding on diets high in saturated fats.

Which molecular effectors of skeletal muscle thermogenesis might be under the control of PI3K and AMPK signaling, and what factors contribute to such early impairments in these signaling pathways (i.e. impairments that precede excess adiposity, circulating FFAs or intramyocellular lipids) are questions that have only recently been the subject of investigations. Of particular interest is demonstration that rats showing catch-up fat owing to suppressed thermogenesis also show diminished mitochondrial mass and oxidative capacity specifically in the subsarcolemmal compartment of skeletal muscle. ${ }^{96}$ Given the important role that subsarcolemmal mitochondria have for bioenergetic support of signal transduction and substrate transport, ${ }^{97}$ the possibility arises that deficiency in this subpopulation of mitochondria could contribute to impaired PI3K and AMPK signaling. Although a reduction in the number of subsarcolemmal mitochondria per se could contribute to the suppression of thermogenesis that favors catch-up fat, impairments in PI3K or in AMPK could also lead to a slow down of a 'futile' substrate cycling between de novo lipogenesis and lipid oxidation. This thermogenic effector has recently been implicated in hormonal control of skeletal muscle thermogenesis, with PI3K being required in controlling the flux of substrates through de novo lipogenesis, and AMPK being required in controlling the flux of de novo synthesized fatty acids through mitochondrial $\beta$ oxidation. ${ }^{93,94,98}$

A role for stearoyl-CoA desaturase (SCD1), the enzyme that catalyzes the synthesis of monounsaturates from saturated fatty acids (in particular from de novo synthesized fatty acids), has also been implicated in the control of this 'futile' substrate cycle, albeit during catch-up fat on a highcarbohydrate (low-fat) diet. This follows the demonstration that SCD1, which is known to be markedly repressed by thermogenic hormones (e.g. leptin and thyroid hormones), is upregulated in skeletal muscle of rats showing catch-up fat driven by suppressed thermogenesis during refeeding on a high-carbohydrate chow diet. ${ }^{99}$ Such an elevated skeletal muscle SCD1, by desaturating the products of de novo lipogenesis and diverting them away from mitochondrial oxidation, would also result in the slowing down of the substrate cycling between de novo lipogenesis and lipid oxidation thereby contributing to the suppression of thermogenesis that drives catch-up fat. Furthermore, as the SCD1-derived monounsaturates in skeletal muscle from animals refed the high carbohydrate diet are channeled towards the phospholipids (membrane) fraction, ${ }^{99}$ and as SCD1 overexpression in skeletal muscle cells leads to impaired insulin signaling, ${ }^{100}$ an upregulated SCD1 can also be implicated in the mechanisms that crosslink suppressed thermogenesis and insulin resistance in skeletal muscle. Of particular relevance in this context are the findings that the enhanced thermogenesis in mice lacking SCD1 can be associated with increases in the activities of skeletal muscle PI3K and AMPK. ${ }^{101-102}$

Overall therefore, there is emerging evidence for insulin and leptin resistance in the early phase of catch-up fat, and for impairments in PI3K and AMPK signaling in skeletal muscle in the mechanisms by which suppressed thermogenesis might crosslink with insulin resistance during catch-up growth. Consequently, impairments in these signaling pathways in skeletal muscle may constitute the molecular basis by which the thrifty metabolism (suppressed thermogenesis) that accelerates fat recovery confers enhanced susceptibility to the development of insulin resistance and hyperinsulinemia during catch-up growth.

\section{Thrifty metabolism driving catch-up fat: adaptive, maladaptive and early programming}

It can be argued that the biological significance of this thrifty metabolism underlying catch-up fat - characterized by concurrent hyperinsulinemia, skeletal muscle insulin resistance and adipose tissue insulin hyperresponsiveness - is to achieve both blood glucose homeostasis and the rapid replenishment of the fat stores by diverting glucose spared from oxidation in skeletal muscle to lipogenesis and fat storage in adipose tissue. Under conditions of intermittent periods of food availability that prevailed during much of mammalian evolution, this coordinated redistribution of glucose from muscle to adipose tissue probably had survival value as it enables the rapid replenishment of fat stores, and hence rapid restoration of survival capacity, without compromising blood glucose homeostasis. Despite its 'adaptive' nature within the context of a lifestyle of famine-and-feast, this state may have deleterious consequences in the context of the modern lifestyle, characterized by low physical activity and energy-dense diets rich in fat and refined carbohydrates. In fact, a shift in diet from complex carbohydrates to animal fat and refined carbohydrates leads to an exacerbated suppression of thermogenesis, a more pronounced state of hyperinsulinemia, hyperglycemia and 


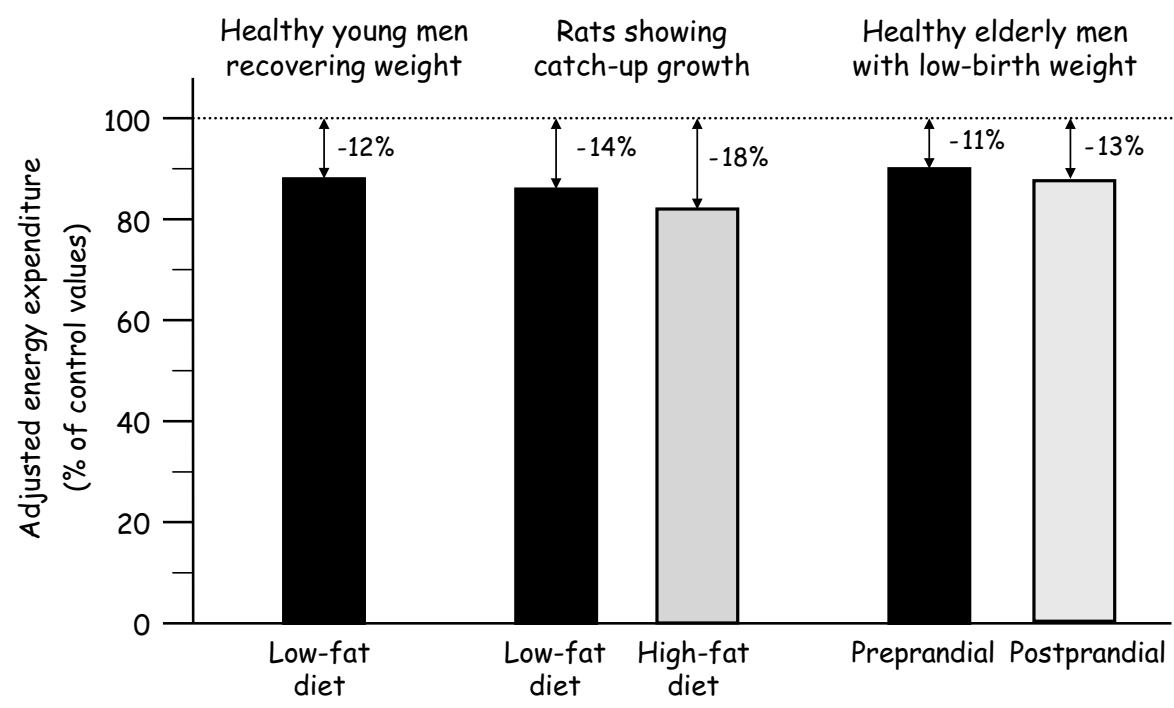

Figure 6 Extent of suppressed thermogenesis (thrifty metabolism) in the compartments of resting energy expenditure (REE) in young men or rats showing preferential catch-up fat after semistarvation, as well as in weight-stable healthy elderly men with low-birth weight. The reduction in adjusted REE is relative to control values set at $100 \%$ (dotted line). Note: (a) the value for extent of suppressed thermogenesis (as \% of baseline BMR) in healthy young men recovering body weight after semistarvation is derived from the Minnesota Experiment of Keys et al., ${ }^{62}$ and were determined in a reanalysis of the data on their BMR after adjustments for changes in FFM and in fat mass relative to prestarvation values, ${ }^{74,84}$ (b) in rats showing catch-up growth after post-weaning semistarvation, REE is taken as their total energy expenditure (essentially sedentary) relative to that of weight-matched controls consuming the same amount of energy and gaining protein mass at the same rate, whether during refeeding on a low-fat diet or on an isocaloric diet rich in animal saturated fat, ${ }^{79,90}$ and (c) in the group of healthy elderly men with lowbirth weight relative to another group with high-birth weight, REE was determined from measurements of both preprandial and post-prandial REE adjusted for body weight and height; in this study by Kensara et al., ${ }^{103}$ the adjustements of REE for FFM, muscle mass, non-muscular (fat-free soft tissue) mass, or for the ratio of muscle to non-muscle (fat-free soft tissue) mass also yielded lower REE values (by 8-12\%) in the low-birth weight group than in the high birth-weight group.

Table 1 Role of suppressed thermogenesis in susceptibility to hyperinsulinemia and glucose intolerance during catch-up fat in the rat

\begin{tabular}{lcccl}
\hline $\begin{array}{l}\text { Refeeding } \\
\text { diets }\end{array}$ & $\begin{array}{c}\text { Thermogenesis } \\
\text { Low fat }\end{array}$ & $\begin{array}{c}\text { Rate of fat } \\
\text { gain }\end{array}$ & $\begin{array}{l}\text { Plasma insulin } \\
\text { concentrations }\end{array}$ & Glucose tolerance \\
\hline High fat & $\downarrow$ & $\uparrow$ & $\uparrow$ & Normal (euglycemic) \\
& $\downarrow \downarrow$ & $\uparrow \uparrow$ & $\uparrow \uparrow$ & $\begin{array}{l}\text { Impaired } \\
\text { (hyperglycemic) }\end{array}$ \\
\hline
\end{tabular}

$\downarrow$ : suppressed; $\downarrow \downarrow$ : further suppressed; $\uparrow:$ elevated; $\uparrow \uparrow$ further elevated. Data summarized from Ref. Crescenzo et al. ${ }^{90}$

excess adiposity in animals recovering weight, compared with fed controls growing spontaneously on isocaloric amounts of the same high-fat diet. ${ }^{90}$ As depicted in Table 1, high levels of (saturated) fat in the diet, even in the absence of hyperphagia, has compromised a complex homeostatic system. To what extent this disruption of glycemia resides in an exacerbated state of skeletal muscle insulin resistance and/or in the inability of adipose tissue to dispose of excess glucose spared as a result of an exacerbated suppression of thermogenesis during high-fat refeeding is currently under investigation. Whatever the answers to these questions, however, it is clear that as the phase of weight recovery/ catch-up growth may last for several months to several years in humans, ${ }^{16,62}$ the drive to suppressed thermogenesis for the purpose of sparing glucose for catch-up fat, via its orchestration through insulin resistance in skeletal muscle and altered insulin responsiveness in adipose tissue, constitute a thrifty phenotype that predisposes individuals with catch-up growth to insulin resistance and risks for later metabolic syndrome. That such thrifty metabolism may also be programmed earlier in fetal or neonatal life, and hence long-lasting so as to operate beyond the phase of catch-up growth seems plausible in the light of evidence, depicted in Figure 6, indicating a lower resting energy expenditure (even after adjustments for weight, height or lean tissue mass) in a group of elderly adults with low birth weight and showing a twofold greater prevalence of metabolic syndrome than in those with a high birth weight. ${ }^{103}$ In the complex interactions between the genetic constitution of the individual, programming or imprinting early in life, and a subsequent lifestyle of energy dense foods and low physical activity, the thrifty 'catch-up fat' phenotype - which evolved to increase survival capacity in a hunter-gatherer lifestyle of periodic food shortages - is a central event in growth trajectories to obesity and to diseases that cluster into the insulin resistance (metabolic) syndrome.

\section{Acknowledgements}

This work is funded by the Swiss National Science Research Foundation (Grants \# 3200-B0-102156 and \# 3200B0113634). 


\section{References}

1 Hamm P, Shekelle RB, Stamler J. Large fluctuations in body weight during young adulthood and twenty-five-year risk of coronary death in men. Am J Epidemiol 1989; 129: 312-318.

2 Lissner L, Bengtsson C, Lapidus L, Larsson B, Bengtsson B, Brownell K. Body weight variability and mortality in the Gothenburg prospective studies of men and women. In: Bjorntorp P, Rossner S (eds). Obesity in Europe 88. John Libbey: UK, 1989, pp 55-60.

3 Holbrook TL, Barrett-Connor E, Wingard D. The association of lifetime weight and weight control patterns with diabetes among men and women in an adult community. Int J Obes Rel Metab Disord 1989; 13: 723-729.

4 Lissner L, Odell PM, D'Agostino RB, Stokes J, Kreger BE, Belanger AJ et al. Variability of body weight and health outcomes in the Framingham population. $N$ Engl J Med 1991; 324: 1839-1844.

5 Lee IM, Paffenbarger RS. A 27-year follow-up of middle-aged men. JAMA 1992; 268: 2045-2049.

6 Diaz VA, Mainous AG, Everett CJ. The association between weight fluctuation and mortality: results from a populationbased cohort study. J Commun Health 2005; 30: 153-165.

7 Montani JP, Viecelli AK, Prévot A, Dulloo AG. Weight cycling during growth and beyond: a risk factor for later cardiovascular diseases. Int J Obes Rel Metab Disord 2006; 30: S58-S66.

8 Yatsuya H, Tamakoshi K, Yoshida T, Hori Y, Zhang H, Ishikawa M et al. Association between weight fluctuation and fasting insulin concentration in Japanese men. Int J Obes Relat Metab Disord 2003; 27: 478-483.

9 Zhang H, Tamakoshi K, Yatsuya H, Murata C, Wada K, Otsuka R et al. Long-term body weight fluctuation is associated with metabolic syndrome independent of current body mass index among Japanese men. Circ J 2005; 69: 13-18.

10 Taeko K, Shigeki T, Hiroshi S, Yuzo S. Effects of weight cycling on young women. Obesity Rev 2006; 7 (Suppl 2): 181 (Abstract).

11 Eriksson JG, Forsen T, Tuomilehto J, Winter PD, Osmond C, Barker DJ. Catch-up growth in childhood and death from coronary heart disease: longitudinal study. BMJ 1999; 318: 427-431.

12 Cianfarani S, Germani D, Branca F. Low birth weight and adult insulin resistance: the 'catch-up growth' hypothesis. Arch Dis Child Fetal Neonatal Ed 1999; 81: F71-F73.

13 Huxley RR, Shiell AW, Law CM. The role of size at birth and postnatal catch-up growth in determining systolic blood pressure: a systematic review of the literature. J Hypertens 2000; 18: 815-831.

14 Ong KK, Ahmed ML, Emmett PM, Preece MA, Dunger DB. Association between postnatal catch-up growth and obesity in childhood: prospective cohort study. BMJ 2000; 320: 967-971.

15 Levy-Marchal C, Jaquet D, Czernichow P. Long-term metabolic consequences of being born small for gestational age. Semin Neonatol 2000; 9: 67-74.

16 Barker DJ, Osmond C, Forsen TJ, Kajantie E, Eriksson JG. Trajectories of growth among children who have coronary events as adults. N Engl J Med 2005; 353: 1802-1809.

17 Popkin BM, Richards MK, Monteiro CA. Stunting is associated with overweight in children of four nations that are undergoing nutrition transition. J Nutr 1996; 126: 3009-3016.

18 Levitt NS, Lambert EV, Woods D, Hales CN, Andrew R, Seckl JR. Impaired glucose tolerance and elevated blood pressure in low birth weight, non-obese, young South African adults: early programming of cortisol axis. J Clin Endocrinol Metabol 2000; 85: 4611-4618.

19 Victora CG, Barros FC. The catch-up dilemma - relevance of Leitch's 'low-high' pig to child growth in developing countries. Int J Epidemiol 2001; 30: 217-220.

20 Sawaya AL, Martins P, Hoffman D, Roberts SB. The link between childhood undernutrition and risk of chronic diseases in adulthood: a case study of Brazil. Nutr Rev 2003; 61: 168-175.
21 Bavdekar A, Yajnik CS, Fall CH, Bapat S, Pandit AN, Deshpande $\mathrm{V}$ et al. Insulin resistance syndrome in 8-year-old Indian children: small at birth, big at 8 years, or both? Diabetes 1999; 48: 2422-2429.

22 Singhal A, Fewtrell M, Cole TJ, Lucas A. Low nutrient intake and early growth for later insulin resistance in adolescents born preterm. Lancet 2003; 361: 1089-1097.

23 Hofman PL, Regan F, Jackson WE, Jefferies C, Knight DB, Robinson EM et al. Premature birth and later insulin resistance. N Engl J Med 2004; 351: 2179-2186.

24 Euser AM, Finken MJ, Keijzer-Veen MG, Hille ET, Wit JM, Dekker FW. Associations between prenatal and infancy weight gain and BMI, fat mass, and fat distribution in young adulthood: a prospective cohort study in males and females born very preterm. Am J Clin Nutr 2005; 81: 480-487.

25 Finken MJ, Keijzer-Veen MG, Dekker FW, Frolich M, Hille ET, Romijn JA et al. Preterm birth and later insulin resistance: effects of birth weight and postnatal growth in a population based longitudinal study from birth into adult life: Insulin resistance 19 years after preterm birth. Diabetologia 2006; 49: 478-485.

26 Rolland-Cachera MF, Deheeger M, Bellisle F, Sempe M, GuilloudBataille M, Patois E. Adiposity rebound in children: a simple indicator for predicting obesity. Am J Clin Nutr 1984; 39: 129-135.

27 Taylor RW, Grant AM, Goulding A, Williams SM. Early adiposity rebound: review of papers linking this to subsequent obesity in children and adults. Curr Opin Clin Nutr Metab Care 2005; 8: 607612.

28 Eriksson JG, Forsen T, Tuomilehto J, Osmond C, Barker DJ. Early adiposity rebound in childhood and risk of type 2 diabetes in adult life. Diabetologia 2003; 46: 190-194.

29 Bhargava SK, Sachdev HS, Fall CH, Osmond C, Lakshmy R, Barker DJ et al. Relation of serial changes in childhood bodymass index to impaired glucose tolerance in young adulthood. $N$ Engl J Med 2004; 350: 865-875.

30 Wadsworth M, Butterworth S, Marmot M, Ecob R, Hardy R. Early growth and type 2 diabetes: evidence from the 1946 British birth cohort. Diabetologia 2005; 48: 2505-2510.

31 Rolland-Cachera MF, Deheeger M, Akrout M, Bellisle F. Influence of macronutrients on adiposity development: a follow up study of nutrition and growth from 10 months to 8 years of age. Int $J$ Obes Relat Metab Disord 1995; 19: 573-578.

32 Hales CN, Barker DJ. The thrifty phenotype hypothesis. Br Med Bull 2001; 60: 5-20.

33 Young JB. Programming of sympathoadrenal function. Trends Endocrinol Metab 2002; 13: 381-385.

34 Colle E, Schiff D, Andrew G, Bauer CB, Fitzhardinge P. Insulin responses during catch-up growth of infants who were small for gestational age. Pediatrics 1976; 57: 363-371.

35 Crowther NJ, Cameroun N, Trusler J, Gray IP. Association between poor glucose tolerance and rapid post natal weight gain in seven-year-old children. Diabetologia 1998; 41: 1163-1167.

36 Ong KK, Dunger DB. Birth weight, infant growth and insulin resistance. Eur J Endocrinol 2004; 151 (Suppl 3): U131-U139.

37 Soto N, Bazaes RA, Pena V, Salazar T, Avila A, Iniguez G et al. Insulin sensitivity and secretion are related to catch-up growth in small-for-gestational-age infants at age 1 year: results from a prospective cohort. J Clin Endocrinol Metab 2003; 88: 3645-3650.

38 Dulloo AG, Jacquet J, Montani JP. Pathways from weight fluctuations to metabolic diseases: focus on maladaptive thermogenesis during catch-up fat. Int J Obes Relat Metab Disord 2002; 26 (Suppl 2): S46-S57.

39 Widdowson EM, Shaw WT. Full and empty fat cells. Lancet 1973; 2: 905.

40 Ashworth A. Growth rates in children recovering from proteincalorie malnutrition. Br J Nutr 1969; 23: 835-845. 
41 Garrow JS, Fletcher K, Halliday D. Body composition in severe infantile malnutrition. J Clin Invest 1965; 44: 417-425.

42 Graham GG, Cordano A, Blizzard RM, Cheek BD. Infantile malnutrition. Changes in body composition during nutritional rehabilitation. Pediatr Res 1969; 3: 579-589.

43 MacLean WC, Graham GG. The effect of energy intake on nitrogen content of weight gained by recovering malnourished infant. Am J Clin Nutr 1980; 33: 903-909.

44 Jackson AA. Nutritional adaptation in disease and recovery. In: Blaxter K, Waterlow JC (eds). Nutritional Adaptation in Man. John Libbey and Company Ltd., London, UK, 1984, pp 111-126.

45 Castilla-Serna L, Pérez-Ortiz B, Cravioto J. Patterns of muscle and fat mass repair during recovery from advanced infantile proteinenergy malnutrition. Eur J Clin Nutr 1996; 50: 392-397.

46 Benefice E, Garnier D, Simondon KB, Malina RM. Relationship between stunting in infancy and growth and fat distribution during adolescence in Senegalese girls. Eur J Clin Nutr 2001; 55: $50-58$.

47 Martins PA, Hoffman DJ, Fernandes MT, Nascimento CR, Roberts SB, Sesso R et al. Stunted children gain less lean body mass and more fat mass than their non-stunted counterparts: a prospective study. Br J Nutr 2004; 92: 819-825.

48 Jornayvaz FR, Selz R, Tappy L, Theintz GE. Metabolism of oral glucose in children born small for gestational age: evidence for an impaired whole body glucose oxidation. Metabolism 2004; 53 : 847-8851.

49 Ibanez L, Ong K, Dunger DB, de Zegher F. Early development of adiposity and insulin resistance after catch-up weight gain in small-for-gestational-age children. J Clin Endocrinol Metab 2006; 91: 2153-2158.

50 Modi N, Thomas EL, Harrington TA, Uthaya S, Dore CJ, Bell JD. Determinants of adiposity during preweaning postnatal growth in appropriately grown and growth-restricted term infants. Pediatr Res 2006; 60: 345-348.

51 Eriksson J, Forsen T, Tuomilehto J, Osmond C, Barker D. Size at birth, fat-free mass and resting metabolic rate in adult life. Horm Metab Res 2002; 34: 72-76.

52 Kensara OA, Wootton SA, Phillips DI, Patel M, Jackson AA, Elia $\mathrm{M}$. Fetal programming of body composition: relation between birth weight and body composition measured with dual-energy X-ray absorptiometry and anthropometric methods in older Englishmen. Am J Clin Nutr 2005; 82: 980-987.

53 Rasmussen EL, Malis C, Jensen CB, Jensen JE, Storgaard H, Poulsen $\mathrm{P}$ et al. Altered fat tissue distribution in young adult men who had low birth weight. Diabetes Care 2005; 28: 1511153.

54 Hermann TS, Rask-Madsen C, Ihlemann N, Dominguez H, Jensen CB, Storgaard $\mathrm{H}$ et al. Normal insulin-stimulated endothelial function and impaired insulin-stimulated muscle glucose uptake in young adults with low birth weight. $J$ Clin Endocrinol Metab 2003; 88: 1252-1257.

55 Ozanne SE, Jensen CB, Tingey KJ, Storgaard H, Madsbad S, Vaag AA. Low birthweight is associated with specific changes in muscle insulin-signalling protein expression. Diabetologia 2005; 48: 547-552.

56 Uthaya S, Thomas EL, Hamilton G, Dore CJ, Bell J, Modi N. Altered adiposity after extremely preterm birth. Pediatr Res 2005; 57: 211-215.

57 Dietz WH. 'Adiposity rebound': reality or epiphenomenon? Lancet 2000; 356: 2027-2028.

58 Williams SM. Weight and height growth rate and the timing of adiposity rebound. Obes Res 2005; 13: 1123-1130.

59 Taylor RW, Goulding A, Lewis-Barned NJ, Williams SM. Rate of fat gain is faster in girls undergoing early adiposity rebound. Obes Res 2004; 12: 1228-1230.

60 Jamin F, Müller E. Specific weight of the living man with clinical applications for recovery of body weight. Münchener Medizinische Wochenschrift 1903; 50: 1454-1457; 1511-1515.
61 Debray C, Zarakovitch M, Ranson B, Jacquemin J, Robert J, Siraga M. Contribution to the study on the pathology of the deportees. Seminaire Hôpital de Paris 1946; 22: 863-870.

62 Keys A, Brozek J, Henschel A, Mickelson O, Taylor HL. The Biology of Human Starvation. University of Minnesota Press: Minneapolis, MN, 1950.

63 Dulloo AG, Jacquet J, Girardier L. Poststarvation hyperphagia and body fat overshooting in humans: a role for feedback signals from lean and fat tissues. Am J Clin Nutr 1997; 65: 717-723.

64 Weyer C, Walford RL, Harper IT, Milner M, MacCallum T, Tataranni PA et al. Energy metabolism after 2 y of energy restriction : the Biosphere 2 experiment. Am J Clin Nutr 2000; 72: 946-953.

65 Barac-Nieto M, Spurr GB, Lotero H, Maksud MG, Dahners HW. Body composition during nutritional repletion of severely undernourished men. Am J Clin Nutr 1979; 32: 981-991.

66 Mitchell PB, Truswell AS. Body composition in anorexia nervosa and starvation. In: Beaumont PJV, Burrows GD, Casper RC (eds). Handbook of Eating Disorders. Part I: Anorexia and Bulimia Nervosa. Elsevier: Amsterdam, 1987, pp 45-77.

67 Van Eys J. Nutrition and cancer. Ann Rev Nutr 1985; 5: 435-461.

68 Streat SJ, Brodie AH, Hill GL. Aggressive nutritional support does not prevent protein loss despite fat gain in septic intensive care. I Trauma 1987; 27: 262-266.

69 Kotler DP, Tierney AR, Culpepper-Morgan JA, Wong J, Pierson Jr RM. Effect of parenteral nutrition on body composition in patients with acquired immunodeficiency syndrome. JPEN 1990; 14: 454-458.

70 Dulloo AG, Montani JP. Obesity in Parkinson's disease patients on electrotherapy: collateral damage, adiposity rebound or secular trends? Br J Nutr 2005; 93: 417-419.

71 Mayer L, Walsh BT, Pierson Jr RN, Heymsfield SB, Gallagher D, Wang $\mathrm{J}$ et al. Body fat redistribution after weight gain in women with anorexia nervosa. Am J Clin Nutr 2005; 81: 1286-1291.

72 Ounsted M, Sleigh G. The infant's self-regulation of food intake and weight gain. Difference in metabolic balance after growth constraint or acceleration in utero. Lancet 1975; 1 (7922): 13931397.

73 Webster AJF. Energy partitioning, tissue growth and appetite control. Proc Nutr Soc 1993; 52: 69-76.

74 Dulloo AG, Jacquet J, Girardier L. Autoregulation of body composition during weight recovery in humans : the Minnesota Experiment revisited. Int J Obes 1996; 20: 393-405.

75 Miller DS, Wise A. The energetics of 'catch-up' growth. Nutr Metab 1976; 20: 125-134

76 Boyle PC, Storlien LH, Keesey RE. Increased efficiency of food utilization following weight loss. Physiol Behav 1978; 21: 261264.

77 Boyle PC, Storlien LH, Harper AE, Keesey RE. Oxygen consumption and locomotor activity during restricted feeding and realimentation. Am J Physiol 1981; 241: R392-R397.

78 Hill JO, Fried SK, Digirolamo M. Effects of fasting and restricted refeeding on utilization of ingested energy in rats. Am J Physiol 1984; 247: R318-R327.

79 Dulloo AG, Girardier L. Adaptive changes in energy expenditure during refeeding following low calorie intake: evidence for a specific metabolic component favouring fat storage. Am J Clin Nutr 1990; 52: 415-420.

80 Dulloo AG, Girardier L. Adaptive role of energy expenditure in modulating body fat and protein deposition during catch-up growth after early undernutrition. Am J clin Nutr 1993; 58: 614621.

81 Evans SA, Messina MM, Knight WD, Parsons AD, Overton JM. Long-Evans and Sprague-Dawley rats exhibit divergent responses to refeeding after caloric restriction. Am J Physiol 2005; 288: R1468-R1476.

82 MacLean PS, Higgins JA, Johnson GC, Fleming-Elder BK, Donahoo WT, Melanson EL et al. Enhanced metabolic efficiency 
contributes to weight regain after weight loss in obesity-prone rats. Am J Physiol 2004; 287: R1306-R1315.

83 Dulloo AG, Jacquet J. An adipose-specific control of thermogenesis in body weight regulation. Int J Obes Rel Metab Disord 2001; 25 (Suppl 5): S22-S29.

84 Dulloo AG, Jacquet J. Adaptive reduction in basal metabolic rate in response to food deprivation in humans: a role for feedback signals from fat stores. Am J Clin Nutr 1998; 68: 599-606.

85 Foster GD, Wadden TA, Kendrick ZV, Letizia KA, Lander DP, Connill AM. The energy cost of walking before and after significant weight loss. Med Sci Sports Exerc 1995; 27: 888-894.

86 Kulkarni R, Shetty P. Net mechanical efficiency during stepping in chronically energy deficient human subjects. Ann Hum Biol 1992; 19: 421-425.

87 Rosenbaum M, Vandenborne K, Goldsmith R, Simoneau JA, Heymsfield S, Joanisse DR et al. Effects of experimental weight perturbation on skeletal muscle work efficiency in human subjects. Am J Physiol 2003; 285: R183-R192.

$88 \mathrm{Ma}$ SW, Foster DO. Starvation-induced changes in metabolic rate, blood flow, and regional energy expenditure in rats. Can J Physiol Pharmacol 1986; 64: 1252-1258.

89 Dulloo AG. A role for suppressed skeletal muscle thermogenesis in pathways from weight fluctuations to the insulin resistance syndrome. Acta Physiol Scand 2005; 184: 295-307.

90 Crescenzo R, Samec S, Antic V, Rohner-Jeanrenaud F, Seydoux J, Montani JP et al. A role for suppressed thermogenesis favouring catch-up fat in the pathophysiology of catch-up growth. Diabetes 2003; 52: 1090-1097.

91 Cettour-Rose P, Samec S, Russell AP, Summermatter S, Mainieri $\mathrm{D}$, Carrillo-Theander $\mathrm{C}$ et al. Redistribution of glucose from skeletal muscle to adipose tissue during catch-up fat: A link between catch-up growth and later metabolic syndrome. Diabetes 2005; 54: 751-756.

92 Dulloo AG, Stock MJ, Solinas G, Boss O, Montani JP, Seydoux J. Leptin directly stimulates thermogenesis in skeletal muscle. FEBS Lett 2002; 515: 109-113.

93 Solinas G, Summermatter S, Mainieri D, Gubler M, Pirola L, Wymann MP et al. The direct effect of leptin on skeletal muscle thermogenesis is mediated by substrate cycling between de novo lipogenesis and lipid oxidation. FEBS Lett 2004; 577: 539-544.

94 Solinas G, Summermatter S, Mainieri D, Gubler M, Montani JP, Seydoux $\mathrm{J}$ et al. Corticotropin-releasing hormone directly stimulates thermogenesis in skeletal muscle possibly through substrate cycling between de novo lipogenesis and lipid oxidation. Endocrinology 2006; 147: 31-38.

95 Summermatter S, Mainieri D, Russell AP, Seydoux J, Montani JP, Buchala A et al. Skeletal muscle insulin and leptin resistance during early catch-up fat driven by suppressed thermogenesis: a role for impaired PI3K and AMPK signalling. Int J Obes Rel Metab Disord 2006 (Abstract) 30: S70.

96 Crescenzo R, Lionetti L, Mollica MP, Ferraro M, D'Andrea E, Mainieri $\mathrm{D}$ et al. Altered skeletal muscle subsarcolemmal mitochondrial compartment during catch-up fat after caloric restriction. Diabetes 2006; 55: 2286-2293

97 Hood D. Plasticity in skeletal, cardiac, and smooth muscle: contractile activity-induced mitochondrial biogenesis in skeletal muscle. J Appl Physiol 2001; 90: 1137-1157.

98 Dulloo AG, Gubler M, Montani JP, Seydoux J, Solinas G. Substrate cycling between de novo lipogenesis and lipid oxidation: a thermogenic mechanism against skeletal muscle lipotoxicity and glucolipotoxicity. Int J Obes Relat Metab Disord 2004; 28 (Suppl 4): S29-S37.

99 Mainieri D, Summermatter S, Rusconi S, Russell AP, Seydoux J, Montani JP et al. A role for stearoyl-CoA desaturase in control of thermogenesis. FASEB J 2006; 20: 1751-1753.

100 Voss MD, Beha A, Tennagels N, Tschank G, Herling AW, Quint M et al. Gene expression profiling in skeletal muscle of Zucker diabetic fatty rats: implications for a role of stearoyl-CoA desaturase 1 in insulin resistance. Diabetologia 2005; 48: 2622 2630.

101 Rahman SM, Dobrzyn A, Dobrzyn P, Lee SH, Miyazaki M, Ntambi JM. Stearoyl-CoA desaturase 1 deficiency elevates insulin-signaling components and down-regulates protein-tyrosine phosphatase 1B in muscle. Proc Natl Acad Sci USA 2003; 100: 11110-11115.

102 Dobrzyn A, Dobrzyn P, Lee SH, Miyazaki M, Cohen P, Asilmaz E et al. Stearoyl-CoA desaturase-1 deficiency reduces ceramide synthesis by downregulating serine palmitoyltransferase and increasing beta-oxidation in skeletal muscle. Am J Physiol 2005; 288: E599-E607.

103 Kensara OA, Wootton SA, Phillips DI, Patel M, Hoffman DJ, Jackson AA et al. Substrate-energy metabolism and metabolic risk for cardiovascular disease in relation to fetal growth and adult body composition. Am J Physiol 2006; 291: E365-E371. 